\title{
Mining for Focus and Priorities in Donald Trump and Hillary Clinton's Daily Tweets during the 2016 U.S. General Elections
}

\author{
John N. Malala \\ University of Central Florida/Nicholson School of Communication, Orlando, 32816, USA \\ E-mail: johnmalala@ucf.edu \\ Osabuohien P. Amienyi \\ Arkansas State University, Department of Media, Jonesboro, 72467, USA \\ E-mail: osami@astate.edu
}

Received: 10 December 2017; Accepted: 17 January 2018; Published: 08 March 2018

\begin{abstract}
This study presents the results of a content analysis of 2476 tweets posted by Hillary Clinton and Donald Trump during the 2016 presidential election following their official nomination by their respective political parties. The study sought to determine whether the candidates used a focused campaign strategy in their tweets, and whether the tweets revealed priorities based on their focus and the time of the day they were posted. The results show that Clinton posted more tweets, had a more focused campaign than Trump during the same time frame.
\end{abstract}

Index Terms - Twitter, Donald Trump Tweets, Hillary Clinton, American Politics, Social Media Politics, U.S Presidential Elections.

\section{INTRODUCTION}

A prominent feature of political communication in the 21 st Century is the normative use of social media to engage the polity in federal, state, local and municipal elections. Virtually all politicians or people running for office nowadays in the United States, as well as in many other western nations, maintain websites and social media accounts that are integrated in their political campaigns. These web sites and social media portals allow the candidates to publish their stances on the issues as well as to inform readers of the candidates' daily activities [1]. A social media portal that seems to have captured the imagination of users more than the others is Twitter. Twitter came to the scene about a decade ago as microblogging website, but quickly became one of the most used sites. On July 1, 2017 Twitter was ranked the third most popular social networking site, after Facebook and YouTube, with an estimated 400,000,000 unique monthly visitors [2].

Barak Obama was the first prominent politician in the United States to embrace social media as a political communication tool. Obama had quickly realized the potential effectiveness of social media as a tool for political mobilization. He had adopted Twitter, YouTube, MySpace, Facebook, and podcasting in March 2007 when he was still a senator. As he sought to become the first African American presidential nominee of the Democratic Party in the U.S. in the 2008 presidential campaign, he used social media extensively to promote his vision and agenda for the country, and became the first high profile political candidate to do so. According to some researchers (see [3], [4], and [5]), Obama's success in the 2008 polls can be largely credited to his effective use of social media. Following Obama's success, other politicians began to seriously appreciate the power of social media as a tool for political marketing. But it was not until two years after Obama's election that other politicians began to jump on the social media band wagon.

Previous research suggests that, as with any other mass communication medium, the successful deployment of social media in a marketing campaign depends upon the implementation of a focused strategy (see [6]). A marketing strategy is said to be focused when it vies for the attention of customers in a saturated environment by creating good content that the target audience cares about. This focus is evident in contemporary political campaigns as candidates use social media to reach and maintain direct interactions with constituents and voters [7]. A focused campaign does not preclude contrasting oneself with one's opponent, nor does it preclude one to mention the other party. It is goal-oriented. It usually corresponds to a campaign theme and can easily be identified through the campaign slogan. According to the Business Dictionary online, "A focus strategy is usually employed where the company knows its segment and has products to competitively satisfy its needs." In determining whether a marketing campaign is focused or not, it is important to analyze messages that are sent during a campaign in order to determine the consistency of the message during the entire campaign period. 
The 2016 election year is particularly noteworthy because of the historical "first" established by the competing candidates. For the first time in the US history, a woman, Hillary Clinton, won the presidential nomination of a major political party. Similarly, a political outsider, private businessman Donald Trump, won the Republican presidential nomination against the odd. Both candidates did not enjoy favorable public opinion. To win over a skeptical audience, both candidates used the social network, Twitter, to promote themselves and to counter their opponent's messages. By so doing, the 2016 presidential elections redefined the meaning of political communication as both candidates used Twitter heavily not only to position themselves, but also to undermine the electability of their opponent. Social media were the battleground for ideas [8]. Because of his tweeting pattern, several newspapers and television networks constantly criticized Trump's middle of the night tweets, which later earned him the title of "Tweeter-in-Chief." See ([9], [10], [11]).

The Clinton campaign claimed that Trumps tweets were a reaction to perceived provocations. Clinton characterized Trump as being out of control with his tweets. During the first presidential debate at Hofsra University on September 26, 2016, Clinton referred to Donald Trump as "one who can be easily provoked by a tweet." Four days later, she repeated this assertion in a tweet adding, "A man who can be provoked by a tweet should not be anywhere near the nuclear codes" [12]. This claim suggested that Trump's repeated tweets were usually reactive to situations and events, rather than being part of a well-thought strategy of focused marketing campaign.

To interrogate this claim, the present study explored the extent to which determine the extent to which Tweets posted by Hillary Clinton and Donald Trump during the 2016 presidential election campaign constituted a "focused marketing strategy." That is, the extent to which Clinton and Trump's campaign tweets repeated the same message, regardless of the format in which these messages were presented to the public?" Specifically, the goal was not only to understand the driving force behind the Tweets, but also to attempt to decipher the candidates' preoccupations through what they truly wanted the voters to know. Were the candidates more concerned about his/her opponent and so focused his/her Tweets on the other person? Were they more concerned about tweeting their own plans? Did the Tweets reveal a clear campaign direction for both candidates? Were the candidate's policy priorities discernable through the Tweets? To address these objectives, the following research questions were posed:

RQ1: During what time of day did Clinton and Trump post the greater number of tweets?

RQ2: What was the object of both candidates' campaign tweets: self-promotion or opponent attack?

RQ3: What was the tone of both candidates' campaign tweets: casual, corporate or offensive?

RQ4: What was the use of branding taglines in the candidates' tweets?

RQ5: To what extent did Clinton and Trump tweet reflect a focused campaign message?

\section{RELATED WORKS}

Several studies have been conducted recently in the area of data mining [33] [34] [35] [36], yet none has focused on political content comprised in the plethora of tweets that are shared daily. Related works have portrayed social media as being a forum for personal marketing where politicians reveal their chosen personality through what they post [13]. Effectively, candidates for political offices use their social media identity to reflect who they are and how they want to be perceived by the public. For candidates who need to boost their profile, social media can be a powerful tool to attract attention and engage voters [14]. Studies also show that social media change the way candidates react to situations as well as how Americans can respond, support, and gather information about the candidates [1].

Political candidates also use social media to "brand" themselves. Through this branding, political candidates become a commodity. Political candidates use social media to present images to commodify themselves, and that can be bought or sold [15]. Researchers believe that Barack Obama became a brand during his 2008 presidential campaigns and that this branding shifted Obama's campaign away from "platform centric" marketing to a "candidate-centered" marketing model [15]. This model sold Obama as a total package. Thus, for all political candidates, social media can serve as a showcase or a campaign poster, which allows users to add details about their hobbies, interests, political views, and socio-demographic characteristics [16].

In 2016, researchers [17] analyzed Donald Trump and Hillary Clinton's campaign tweets, as well as their campaign websites to determine each candidate's PR campaign strategy before they were established as their parties' frontrunners. Specifically, their study examined differences in the ways in which the candidates presented themselves and communicated with voters through their websites and Twitter. A content analysis of a small sample of candidates' websites and tweets ( $\mathrm{N}=\mathrm{T} 295$, C228) revealed significant differences in their emphasis on traits and issues, main content of tweet, main source of retweet, multimedia use, and the level of civility. This study found consistent differences between the two frontrunners in that Clinton emphasized her masculine traits and women issues more than her feminine traits and men issues. Conversely, the study found that Trump gave more weight to men issues while paying no attention to his personal traits. Trump was also found to utilize mostly user-generated content as sources of his tweets while three quarters of Clinton's tweets were original content. Finally, the study found that half of Trump's tweets were retweets of and replies to citizens.

Twitter is an important platform that political candidates use to communicate with their electorate, and is increasingly being used for their self-promotion. 
Twitter is used as a vehicle to talk about candidates' private persona, such as their emotions, private life and professional activities [18]. Political leaders use tweets primarily to broadcast information about their policies and their personality [19]. Several studies have focused exclusively on Twitter in the political context ([20], [21], [22], [23]. One of the studies [20] specifically explored the extent to which Twitter may influences or be influenced by national newspapers. Specifically, they explored how political campaigns and parties relied on the major news outlets to provide content for their regular Twitter posts, or content which are used to communicate a unique agenda that may then predict media content. Additionally, they sought to determine how the news sites were used to promote their campaigns, as well as to observe the attitude the candidates had towards their supporters and constituents. This analysis enabled the researchers to understand the value the politicians placed on certain issues in the society.

Earlier, in 2013 a group of scholars [24] had analyzed how presidential candidates used Twitter during the 2012 primary election. They wondered whether candidates were consistent in their use of the Tweeter platform and how much familiarity or difficulty they associated with its use. They found that Twitter was the most utilized social media platform by the presidential primary candidates. They said Twitter's low cost and lack of restriction on viewing messages made it a terrific platform for candidates to have unrestricted connections and communications with their constituents.

Similarly, during the same year other scholars [22] investigated how the 2012 US presidential candidates used Twitter to build relationships with their followers through meaningful dialogue. They noted that such relationship was essential to constituent's willingness to advocate on behalf of the candidates. They analyzed Tweets collected from the Twitter pages of the 2012 US presidential candidates within a period of 29 days. They found that Obama was the only 2012 candidate who had some level of engagement with the followers. He asked his followers questions and acknowledged their questions through re-tweeting. They concluded that the candidates who retweeted their follower's comments, appeared to listen more to their constituents. They added that constituents' opinion about presidential candidates subsequently reveals the way the candidates are characterized on their social media platform. This characterization ultimately determines public opinion, voting behavior and outcomes of elections.

During the 2012 U.S. primary elections, a study [25] examined how the 2012 presidential candidates Mitt Romney, Rick Santorum, Newt Gingrich and Ron Paul used Twitter to interact with their audiences and to mobilize their supporters. They analyzed Tweets, extracted from January 5, to January 31, 2012 during the Republican primary campaigns. Their results showed that these candidates used Twitter primarily to announce their campaigns schedules, campaign stops and TV appearances. They noted that while all candidates used Twitter to post schedules and appearances as mobilization tactics, Rick Santorum used these tactics the most. Santorum's mobilization tweets accounted for $40 \%$ of all mobilization tweets posted by all four candidates.

As part of a strategy designed to appeal to young voters, one study [26] observed how Obama's campaign team sent out messages to the electorate to communicate Obama's messages, accompanied with custom-made wall papers, ring tones and a personalized message which spelled OBAMA. This strategy became an exemplar of Barack Obama's use of new media technology to reach voters of all ages and background.

Other researchers have sought to understand political candidates' presence on Twitter by examining their Twitter feeds within specified election periods. Tweets were extracted through diverse methods and analyzed to understand the major interests of the politicians. To determine a candidate's consistent use of Twitter, a team of researchers [27] gathered Twitter feeds and activity levels of candidates from the Republican, Democratic, Libertarian, and Americans Elect parties and their campaigns over a 3-month span. The number of tweets posted, the number of followers an account holder had, and the number of people an account holder chose to follow, were recorded on a nightly basis using the Twitter html data. Computer-assisted content analysis was used to code the number of references under such categories as election issues, campaign-related media, campaign events and donations. Their findings revealed that the frequency of posting on Twitter does not always suggest popularity of the candidate or an increase in followers. However, Twitter is helpful in bringing attention to lesser known candidates.

One researcher [28] observed how social media helped candidates to inform and reinforce their views to voters during the 2012 presidential elections. The author recorded daily campaign tweets within a period of two months. The Tweets were classified as units and a coding system was created to identify the purpose and intention of the campaign. This included what the campaign attempted to achieve by posting the content. He found that each candidate used their accounts to communicate directly to their supporters, primarily about campaign events and candidate features. He concluded that social media provided the opportunities to bypass the mainstream media and to interact directly with individual supporters.

To get a sense of what people were saying in social media about Mitt Romney and Barack Obama, two researchers [29] examined how these candidates were framed by citizens during the 2012 presidential election. They observed the dominant topics discussed and how public sentiment was expressed in the nonpartisan \#election2012 Twitter page of the candidates. Tweets showing status update provided by each candidate as well as comments made by friends and followers were scraped using the Discover Text interface. Their findings revealed that each candidate was endorsed on his page using positive words and expressions, while the opposition candidate was attacked using critical words.

The increase in Twitter use by candidates has informed 
a study of its popularity over traditional media. There exists a relationship whereby one influences or is being influenced by the other. Twitter feeds appears to some extent to predict the agenda of traditional news media regarding issues relating to election, because politicians are increasingly using the platform to communicate an agenda which in turn shapes the media agenda. Researchers [30] explain this relationship, pointing out the influence of Twitter on newspaper coverage and how politicians are able to influence the media and the public during election time. Their findings were generated from an analysis of tweets from the candidates' Twitter feeds and newspapers, in an effort to determine which media preceded the other in issue mentions. Issues relating to elections and the frequency of mentions was presumed to give an indication of the significance attached to such issues.

For example, one team of researchers [31] focused on issues relating to women in the 2012 presidential campaign. They were concerned with the positions held by the 2012 presidential candidates towards women in their political communication. They gathered tweets from President Barack Obama and Mitt Romney's official Twitter accounts within a period of three months. They analyzed photos presented in the tweets to determine whether women and girls were strategically placed in the photos. Their aim was to discover the types of women's issues that were discussed in the tweets and to determine what the issues suggested about the candidates and their platforms. Their results showed that Barack Obama had the most representation of women's issues in his tweets, an indication of how he perceived the importance of women. With this, he could capture the women's vote in the 2012 Presidential Election. Some suggest that it was the record number of women who sent President Barack Obama back to the White House for another four years. Women gave Obama 55\% to Romney's 42\%, a proportion that was unchanged from the president's lead among women in 2008 [31].

In sum, our review shows that social media tools have tremendously influenced political campaigns, and changed the way online information flows. Twitter provides the opportunity to build relationships between candidates and voters which will influence their willingness to advocate on behalf of the candidates. This relationship demands engagement with constituents as well as accountability and more transparency on the part of the candidates. Social media rewards those who know where to find the target audience, connect with that audience by offering a mutually beneficial two-way relationship, and then ask for their votes [28]. Researchers do, indeed, recognize that the pervasiveness of mobile devices used for communication has had mixed effects on human behaviors ([32], [33]). Therefore, the mining of information that occur regularly on computer networked is considered a very critical task that could provide useful information [34], especially if the context of each occurrence is well ascertained [35]. Data also show that the mining research over data stream has been prominent as they can be applied in many alternative areas in the real worlds [36].

\section{METHODOLOGY}

To answer the stated research questions, a content analysis was conducted on tweets posted by Hillary Clinton and Donald Trump following their official nomination by their respective political parties. In order to ensure consistent and fair comparison, data collection started on July 28, 2016 which was the day following the official nomination of Hillary Clinton as the candidate for the Democratic party. The tweets were collected for a period of 100 days until the day of the general elections on November 8, 2016. The first step in the process was to use Twitter's search tool in order to collect all original tweets posted by Donald Trump and Hillary Clinton from July 28 to November 8, 2016. This collection was possible by using a simple algorithm containing the string "From:HillaryClinton since:2016-07-28 until:2016-1108" and "From:realDonaldTrump since:2016-07-28 until 2016-11-08" These strings yielded search results that displayed all original tweets by either candidate during the period of the inquiry. Public replies to the tweets and retweets were excluded from the analysis.

Two graduate students were trained to code the content of each tweet to determine the time of the day the tweet was sent. Each tweet classified into one of the following five-time categories: a) Morning, b) Midday, c) Afternoon, d) Evening, and e) Night. In examining the content of each tweet, coders were asked to read and determine its object. The object consisted of determining whether the candidate's message was (a) a self-promotion, (b) an attack on the opponent, (c) a current event, or (d) something else. The analysis of the message content also sought to determine whether the tone of the tweet. Regardless of the tone, tweets were also analyzed in terms of style. Coders were charged to analyze the style by determining whether the articulation of the message used a language that was (a) corporate, (b) casual, or (c) offensive. Finally, the coders were asked to identify the theme of the message in each Tweet. The theme referred to the use of the campaign slogan such as "Making America Great Again" for Donald Trump, or "Stronger Together" for Hillary Clinton. Each content category was assigned a specific numerical value that was used to produce frequency distributions, and to calculate other parametric and non-parametric statistics.

The collected data was analyzed using IBM SPSS Statistics 23. Frequencies, percentages, means and standard deviations were calculated for each category. Some variables were cross-tabulated and the chi-square test of independence was calculated to compare the candidate's tweets along the four stated content categories. The results were used to draw conclusions about the real drives and priorities in the daily tweets by Hillary Clinton and Donald Trump during the 2016 U.S. General Elections. The objective was to add to existing knowledge relating to the general and specific role of social media portals in political communication. 


\section{RESULTS AND DISCUSSION}

Together, both candidates released a cumulative total of 2,476 original tweets during the three months and oneweek duration of this study. Of these, Clinton had more than half $(1,456)$, while Trump posted 1,020. A chisquare test of independence was performed to compare the time of day when Clinton and Trump posted the greater number of campaign tweets. A significant difference was found $(\chi 2(4)=78.43, p<.01)$. Clinton released more tweets than Trump in the mid-day and afternoon day-part $(57 \%, 71 \%$, respectively), while Trump released more tweets than Clinton in the evening daypart (52\%). Both candidates posted 40 percent of their tweets in the morning.

Table 1. Time of the Day

\begin{tabular}{cccccr}
\hline Candidates & Afternoon & Evening & Mid-Day & Morning & Total \\
\hline Trump & 140 & 311 & 163 & 406 & 1020 \\
Clinton & 189 & 292 & 390 & 585 & 1456 \\
Grand Total & $\mathbf{3 2 9}$ & $\mathbf{6 0 3}$ & $\mathbf{5 5 3}$ & $\mathbf{9 9 1}$ & $\mathbf{2 4 7 6}$ \\
\hline \multicolumn{7}{c}{$\left(\chi^{2}(4)=78.43, \mathrm{p}<.01\right)$}
\end{tabular}

RQ2 sought to determine the primary object of each candidate's campaign tweets. Did the candidates focus their tweets on self-promotion or opponent attack? The results of the calculated chi-square test of independence presented in Table 2 shows a significant difference in the object of Trump and Clinton tweets $\left(\chi^{2}(3)=290.37\right.$, p $<.01)$. Clinton had significantly fewer tweets $(4 \%)$ focused on current events (issues) than Trump (27\%). Forty-four percent of Clinton tweets were devoted to opponent attack, as opposed to 37 percent of Trump tweets. Fifty-two percent of Clinton tweets focused on self-promotion, while 35 percent of Trump tweets were devoted to that same objective.

Table 2. Object of the Tweet

\begin{tabular}{ccccc}
\hline Candidates & Current Event & Opponent & Self & Total \\
\hline Trump & 284 & 378 & 358 & 1020 \\
Clinton & 60 & 641 & 755 & 1456 \\
Total & $\mathbf{3 4 4}$ & $\mathbf{1 0 1 9}$ & $\mathbf{1 1 1 3}$ & $\mathbf{2 4 7 6}$ \\
\hline \multicolumn{5}{r}{$\left(\chi^{2}(3)=290.37, \mathrm{p}<.01\right)$}
\end{tabular}

RQ3 focused on the tone of the candidate's campaign tweets. It asked: was the tone of the tweets was casual, corporate or offensive? A chi-square test of independence was calculated to compare the tone of both candidates' campaign tweets (see Table 3). A significant difference was found in the number of Trump and Clinton tweets that had a casual, corporate or offensive tone $(\chi 2$ (3) $=23.71, \mathrm{p}<.01)$. Trump tweets $(67 \%)$ were slightly more likely to carry a casual tone than Clinton tweets $(60 \%)$. On the other hand, Clinton tweets $(37 \%)$ were slightly more likely to carry an offensive tone than Trump tweets (31\%).

Table 3. Tone of the tweet

\begin{tabular}{cccccc}
\hline Candidates & Casual & Corporate & Offensive & Other & Total \\
\hline Trump & 687 & 5 & 318 & 10 & 1020 \\
Clinton & 867 & 27 & 533 & 29 & 1456 \\
Total & $\mathbf{1 5 5 4}$ & $\mathbf{3 2}$ & $\mathbf{8 5 1}$ & $\mathbf{3 9}$ & $\mathbf{2 4 7 6}$ \\
\hline \multicolumn{7}{c}{$\left(\chi^{2}(3)=23.71, \mathrm{p}<.01\right)$}
\end{tabular}

RQ4 focused on the use of branding taglines in the candidates' tweets. A chi-square test of independence was calculated to compare both candidates' use of taglines, such "Stronger Together" or "Making America Great Again", in their campaign tweets (see Table 4). A significant difference was found $\left(\chi^{2}(1)=56.12, \mathrm{p}<.01\right)$. Trump tweets $(56 \%)$ were more likely to contain tagline than Clinton tweets $(41 \%)$. Conversely, Clinton tweets $(59 \%)$ were more likely to omit the tagline than Trump tweets $(44 \%)$.

Table 4. Branding/Use of Tagline

\begin{tabular}{cccc}
\hline Candidates & $\begin{array}{c}\text { Not Branded } \\
\text { with Tagline }\end{array}$ & $\begin{array}{c}\text { Branded with } \\
\text { Tagline }\end{array}$ & Total \\
\hline Trump & 448 & 572 & 1020 \\
Clinton & 861 & 595 & 1456 \\
Total & $\mathbf{1 3 0 9}$ & $\mathbf{1 1 6 7}$ & $\mathbf{2 4 7 6}$ \\
\hline \multicolumn{4}{c}{$\left(\chi^{2}(1)=56.12, \mathrm{p}<.01\right)$}
\end{tabular}


Table 5 presents the result of a chi-square test of independence calculated to compare the object of the candidates' tweets and time of the day. This was used to address the most significant the question raised by the study, relating to the extent to which Clinton and Trump tweets reflected a focused marketing campaign. When viewed separately, the analysis shows no statistically significant difference in the cross-tabulation of each respective candidate's object of tweet by time of day. In other words, time of day did not appear to vary the object of the tweets released by either Trump $\left(\chi^{2}(6)=11.481 \mathrm{~b}, \mathrm{p}\right.$ $=.075)$ or Clinton $\left(\chi^{2}(6)=5.063, \mathrm{p}=.536\right)$. Trump's tweet objects were almost evenly split between himself, his opponent, and other current events in the morning, mid-day, afternoon, and evening. At any given time of the day (morning, mid-day, afternoon, and evening), more than $95 \%$ of Clinton's tweets were focused on herself first, followed by her opponent.

However, when viewed comparatively, the chi square calculations show statistically significant differences in Trump and Clinton's object of the tweet by the time of day $\left(\chi^{2}(6)=16.183, P=.013\right)$. More than $95 \%$ of Clinton's tweets, at any given time, focused on herself and on her opponent, while only about $72 \%$ of Trump's tweets focused on his opponent and on himself. At any given time, more than a quarter of Trump's tweets (28\%) focused on current events compared to only $4 \%$ of Clinton's. Finally, in general, Clinton (1456 for 59\%) out-tweeted Trump (1020 for $41 \%$ ) by 18 percentage, between the period immediately following the Democratic Convention and the day before the general elections.

Table 5. Cross-tabulation of Candidates Object of tweet by time of day

\begin{tabular}{ccccccc}
\hline \multirow{2}{*}{ Candidates } & Object of Tweet & Morning & Mid-Day & Afternoon & Evening & Total \\
\hline Trump & Current Event & $96(24 \%)$ & $50(30 \%)$ & $52(37 \%)$ & $86(28 \%)$ & 284 \\
& Opponent & $166(41 \%)$ & $58(36 \%)$ & $44(31.5 \%)$ & $110(35 \%)$ & 378 \\
& Self & $144(35 \%)$ & $55(24 \%)$ & $44(31.5 \%)$ & $115(30 \%)$ & 358 \\
Trump Total & & $\mathbf{4 0 6}$ & $\mathbf{1 6 3}$ & $\mathbf{1 4 0}$ & $\mathbf{3 1 1}$ & $\mathbf{1 0 2 0}$ \\
\hline Clinton & Current Event & $26(4 \%)$ & $16(4 \%)$ & $6(3 \%)$ & $12(4 \%)$ & 60 \\
& Opponent & $275(47 \%)$ & $159(41 \%)$ & $83(44 \%)$ & $124(43 \%)$ & 641 \\
& Self & $284(49 \%)$ & $215(55 \%)$ & $100(53 \%)$ & $156(53 \%)$ & 755 \\
\hline Clinton Total & & $\mathbf{5 8 5}$ & $\mathbf{3 9 0}$ & $\mathbf{1 8 9}$ & $\mathbf{2 9 2}$ & $\mathbf{1 4 5 6}$ \\
\hline
\end{tabular}

These results suggest that Donald Trump may not have run a clearly focused campaign. This conclusion is consistent with one of the studies that analyzed the candidates' Twitter PR strategies which concluded that Donald mostly utilized user-generated content as sources of his tweets while three quarters of Clinton's tweets were original content (see Lee \& Lim, 2016). This dependence on user-generated content is an indication of a lack of focus from a PR strategy standpoint. While he won the Electoral College, this apparent absence of clearly articulated priorities seems to have driven his social media campaign which resulted on his loss of the popular vote by nearly three million votes. The nearly a three-way split in his focus, regardless of the time of the day, seem to suggest that his tweets constantly contested between media and user-generated events, his opponent and himself. This was reflected in his use of various hashtags such as \#MAGA, \#CrookedHillary, \#BigLeagueTruth, VOTE.GOP, \#Obamacare, \#DrainTheSwamp, etc. For example, in a single tweet Donald Trump listed bullet points that included "Obamacare, Rigged 2008 elections, Repeal and Replace Obamacare, Radical Islamic terrorists" followed by the hashtag "\#MakingAmericaGreatAgain." It appeared that he wanted to cover as many grounds as possible, but at the same time it validated his opponent accusation who said during one of the presidential debates that Trump "can easily be provoked by a tweet."

Conversely, not only did Clinton's tweets overwhelmingly outnumber Trump's, her social media campaign also appeared to have a clear strategic focus on herself and her opponent. This fixed focus on herself first, then her opponent, at any given time of day, suggested her campaign priorities. As the analysis of the current study showed, Clinton gave no importance to issues that were unrelated to her or to her opponent. Her campaign theme, "\#StrongerTogether", seemed to purposefully label Trump as the architect someone who would be weakening America with a divisive policy, thereby positioning herself as the only viable candidate who could unite the nation for a stronger America. As Sargent (2017) explained in a post-election commentary published by the Chicago Tribune, the majority of those who voted for Trump were responsive to what Trump was selling them on immigration. They felt their life had not gotten better over eight years of Democratic Party rule and thus concluded that Democrats didn't care about them. Meanwhile, Clinton constantly made a strategic concerted effort to establish a contrast between herself and her opponent.

\section{CONCLUSION AND RECOMMENDATION}

The study sought to determine the extent to which both candidates used a focused marketing strategy through Twitter, which was considered the battleground for social media in the days following the nomination of Hilary Clinton as the Democratic presidential candidate to the day before the 2016 U.S. general elections. As indicated earlier, the Clinton-Trump presidential race has not only 
redefined the meaning of political communication, but also that of the word battleground. Social media are gradually overshadowing traditional media as political communication tools, as political candidates are increasingly utilizing them to communicate with the electorate. As the popularity of cyberspace continues to grow and technological advancements continue to emerge, the role it will play in future political campaigns is significant. In order to have a meaningful election, voters must be encouraged to actually vote. Social media are becoming the perfect place for candidates to directly interact with their supporters in a highly personal and interactive manner.

One of the limitations of this study was the fact that retweets and replies were not included in the sample. These replies and retweets may have provided more clarity in on the types of issues that attracted candidates' attention to the point where they felt compel to retweet or to reply. Another major limitation in the study is the broad nature of the content categories and quantification schemes used. This allowed analysis of aggregated data that yield general impressions. A closer look at candidates' attacks on each other show stark differences in the way they were carried out. For example, Trump attacks were so personal that he tagged his opponent by preceding them with "@HillaryClinton" and by using the hashtag "\#CrookedHillary." Hillary Clinton's attacks on Trump almost never tagged her opponent even though she tried to tarnish her opponent's opponent by mentioning the bad things he had said during the campaign and the things that he did with his business. For example, Clinton's tweet "Trump suits were made in Mexico. He could have made them in Brooklyn or Ohio" is categorized as an attack on her opponent, but it is not as uncivil as Trump's tweet that reads, "This is what we can expect from \#CrookedHillary."

Future studies must endeavor to drill down into the content of each tweet, to understand the message each contained and the specific audience targeted. It would be interesting to know how many specific topics can be categorized from the direct message in each. Finally, while some may argue that based on media uproars the sample should have shown that Trump tweeted more than Clinton, the findings support a previous study (Lee \& Lim, 2016) that found that half his tweets were retweets and replies to citizens, which were not the object of this study.

\section{REFERENCES}

[1] J. Johnson, "Twitter bites and Romney: Examining the rhetorical situation of the 2012 presidential election in 140 characters," Journal of Contemporary Rhetoric, Vol. 2, No. 3/4, pp. 54-64, 2012.

[2] eBizMBA, "Top 15 Most Popular Social Networking Sites," The eBusiness Guide, http://www.ebizmba.com/articles/social-networkingwebsites, July1, 2017

[3] B. Bimber, "Digital Media in the Obama Campaigns of 2008 and 2012: Adaptation to the Personalized Political Communication Environment," Journal of Information Technology \& Politics, Vol. 11, No.2, pp. 130-150, 2014.
[4] P. Borah, "Political Facebook use: Campaign strategies used in 2008 and 2012 presidential elections," Journal of Information Technology \& Politics, Vol. 13, No.4, pp. 326-338, 2016.

[5] R. Southern, "Is Web 2.0 Providing a Voice for Outsiders? A Comparison of Personal Web Site and Social Media Use by Candidates at the 2010 UK General Election," Journal of Information Technology \& Politics, Vol. 12, No. 1, pp. 1-17, 2015.

[6] J. Druckman, "Priming the Vote: Campaign Effects in a U.S. Senate Election," Political Psychology, Vol. 25, No. 4, pp. 577-594, 2004.

[7] W.L. Bennett, "The Personalization of Politics: Political Identity, Social Media, and Changing Patterns of Participation," The ANNALS of the American Academy of Political and Social Science, Vol. 644, pp. 20-39, 2012.

[8] J. Keegan, "Clinton vs. Trump: How They Used Twitter," The Wall Street Journal, http://graphics.wsj.com/clintontrum-twitter/, Retrieved online on July 16, 2017.

[9] M. O'Rourke, "Donald Trump: Tweeter in chief," Risk Management, Vol. 64, No.1, p. 40, 2017.

[10] D. Guilford, "Points for tweeter-in-chief to consider," Automotive News, Vol. 91, No. 6759, p. 0012, 2017.

[11] F. Barnes, "Tweeter in Chief", Weekly Standard, Vol. 22, No. 13, pp. 11-12, 2016

[12] H. Clinton, "A man who can be provoked by a tweet should not be anywhere near the nuclear codes," Twitter, https://twitter.com/hillaryclinton/status/781950603366952 960, 2016.

[13] K.C. Desouza, S. Alashri, V. Bajaj, \& S.K. Srinivasa, "Tracking presidential campaigns on Facebook," Washington: Brookings Institution Press, https://ezproxy.library.astate.edu/login?url=http://search.p roquest.com/docview/1797445529? accountid=8363_2016

[14] N. Andrews, "On twitter, 2016 rivals let the jabs fly; potential candidates are using social-media accounts to show policy chops, personality," Wall Street Journal (Online),

https://ezproxy.library.astate.edu/login?url=http://search.p roquest.com/docview/1655567864? accountid=8363,2015

[15] S.M. Zavattaro, "Brand Obama: The implications of a branded president," Administrative Theory \& Praxis, Vol. 32, No. 1, pp. 123-128, 2010.

[16] N. Spierings and K. Jacobs, "Getting personal? The impact of social media on preferential voting," Political Behavior, Vol. 36, No. 1, pp. 215-234. doi:http://dx.doi.org/10.1007/s11109-013-9228-2, 2014

[17] J. Lee and Y. Lim, "Gendered campaign tweets: The cases of Hillary Clinton and Donald Trump," Public Relations Review, Vol. 42, No.5, pp. 849-855, 2016.

[18] S.S. Kruikemeier, "How political candidates use Twitter and the impact on votes," Computers in Human Behavior, Vol. 34, pp. 131-139, 2014.

[19] J.H. Parmelee \& S.L. Bichard, S, "Politics and the Twitter revolution: How tweets influence the relationship between political leaders and the public," Lanham, MD: Rowman and Littlefield Publishing Group, Inc., 2012

[20] See 30.

[21] See 24.

[22] A. Adamsa \& T. McCorkindale, "Dialogue and transparency: A content analysis of how the 2012 presidential candidates used twitter," Public Relations Review, Vol. 39, No. 4, pp. 357-359, 2013.

[23] A.D. Lewandowski, "Obama ${ }^{\mathrm{TM}}$ : Political branding and participation in the 2012 U.S. presidential election," Order No. 1536653, Dissertations \& Theses Global, 1355174698, 2013. 
[24] B.A. Conway, K. Kenski, \& D. Wang, "Twitter use by presidential primary candidates during the 2012 campaign," American Behavioral Scientist, Vol. 57, No. 11, pp. 1596-1610, 2013.

[25] See 23

[26] A.J. Hendricks \& R.E. Denton, "Communicator-in-chief: How Barack Obama used new media technology to win the White House," Lanham, MD: Rowman and Littlefield Publishing Group, Inc., 2010.

[27] See 24.

[28] P. Ryan, "The presidential candidate and social networking - a lesson in self-preservation, Master's thesis, ProQuest Dissertations \& Theses database. (UMI No. 1509061), 2012.

[29] J. Groshek \& A. Al-Raw, "Public sentiment and critical framing in social media content during the 2012 U.S. Presidential Campaign," Social Science Computer Review, pp. 1-14, 2013.

[30] B.A. Conway, K. Kenski, \& D. Wang, "The rise of Twitter in the political campaign: Searching for intermedia agenda-setting effects in the presidential primary," Journal of Computer-Mediated Communication, Vol. 20, No. 4, pp. 363-380, 2015.

[31] S.L. Combs \& M.J. Pitts, "The top two: Their tweets and how they focused on women in the 2012 presidential election," Race, Gender \& Class, Vol. 21, No.1, pp. 169184, 2014.

[32] Malala, John N. (2016). Communication Privacy Management and the Digital Footprint in Pervasive Computer-Mediated Communication. International Journal of Advanced Research in Computer Science, 7 (7), $31-41$.

[33] Rahaman, Mahbobor "The Effects of Mobile Phone Use on Human Behaviors: A Study of Developing Country Like Bangladesh", International Journal of Information Technology and Computer Science(IJITCS), Vol.9, No.11, pp.48-56, 2017. DOI: 10.5815/ijitcs.2017.11.05

[34] Hardeo Kumar Thakur, Anand Gupta, Bhavuk Jain, Ambika,"Mining Maximal Quasi Regular Patterns in Weighted Dynamic Networks", International Journal of Information Technology and Computer Science(IJITCS), Vol.9, No.4, pp.48-62, 2017. DOI: 10.5815/ijitcs.2017.04.07

[35] Melyara. Mezzi, Nadjia. Benblidia,"Study of Context Modelling Criteria in Information Retrieval", International Journal of Information Technology and Computer Science(IJITCS), Vol.9, No.3, pp.28-39, 2017. DOI: 10.5815/ijitcs.2017.03.04

[36] Long Nguyen Hung, Thuy Nguyen Thi Thu,"Mining Frequent Itemsets with Weights over Data Stream Using Inverted Matrix", International Journal of Information Technology and Computer Science(IJITCS), Vol.8, No.10, pp.63-71, 2016. DOI: 10.5815/ijitcs.2016.10.08

\section{Authors' Profiles}

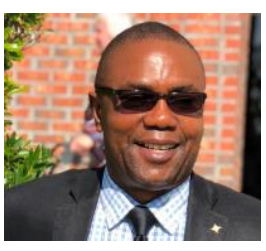

John N. Malala is an Associate Professor of Interactive Multimedia in the Nicholson School of Communication at the University of Central Florida in Orlando, Florida (USA). The author holds a Ph.D. degree in Electronic Imaging and Media Communication from the University of Bradford in the UK where he was a member of the Virtual Environment Research Group. While his doctoral dissertation focuses on virtual learning environments, his research interests include Data Mining, Human-Computer Interaction, Educational Technology, Political Communication, and Cyber Culture.

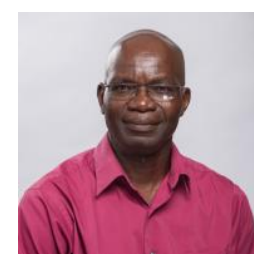

Osabuohien P. Amienyi is Professor and Chair of Media Department at Arkansas State University in the U.S. He holds a Ph.D. in Communication from Bowling Green University, Ohio, USA. He was a film producer and videographer in Nigeria and worked in radio and television in the U.S. His research on national development has appeared in a variety of national and international publications. He is author of the book, Communicating National Integration: Empowering Development in African Countries (Aldershot, UK: Ashgate, 2005), and received a Fulbright Fellowship to teach and conduct research at The University of Malawi - The Polytechnic in 2005. He became chair of the Department of Radio-Television in 2007

How to cite this paper: John N. Malala, Osabuohien P. Amienyi, "Mining for Focus and Priorities in Donald Trump and Hillary Clinton's Daily Tweets during the 2016 U.S. General Elections", International Journal of Information Technology and Computer Science(IJITCS), Vol.10, No.3, pp.1-8, 2018. DOI: 10.5815/ijitcs.2018.03.01 